\title{
PENGHEMATAN ENERGI DENGAN OPTIMALISASI MATERIAL DINDING DAN KACA JENDELA PADA RUMAH SEDERHANA
}

\author{
Yunita Ardianti Sabtalistia \\ Dosen Prodi S1 Arsitektur, Fak. Arsitektur dan Perencanaan, UNTAR Jakarta \\ e-mail:yunitas@ft.untar.ac.id
}

\begin{abstract}
ABSTRAK
Penghematan energi dapat ditempuh dengan mengurangi beban pendinginan. Jika penerimaan radiasi matahari yang diterima oleh kulit bangunan bisa dikurangi maka beban pendinginan dapat berkurang. Dinding dan kaca jendela adalah elemen kulit bangunan yang banyak menerima radiasi matahari. Dinding pada kulit bangunan mempunyai luasan cukup besar sehingga sangat berpengaruh terhadap besar kecilnya penerimaan panas matahari. Kaca jendela merupakan jenis material yang mempunyai U-value tinggi. Penelitian ini bertujuan untuk mengetahui jenis material pada dinding dan kaca jendela yang paling bisa memperkecil penerimaan radiasi matahari (solar heat gain) sehingga dapat menghemat energi untuk pendinginan.

Metode penelitian yang digunakan adalah metode eksperimen. Jenis-jenis material dinding dan kaca jendela dieksperimen dengan Ecotect Analysis 2011 untuk mengetahui pengaruhnya terhadap beban panas akibat radiasi matahari. Studi kasus yang digunakan adalah rumah sederhana tipe 27/60 di Bogor, Jawa Barat. Hasil penelitian membuktikan bahwa dinding double brick cavity plaster paling hemat energi karena paling mampu mengurangi perolehan solar heat gain. Kaca jendela double glazed Low-E aluminium frame juga lebih mampu mengurangi solar heat gain daripada kaca jendela double glazed aluminium frame. Penggantian material dinding lebih efektif dalam mengurangi solar heat gain daripada kaca jendela karena luasan dinding jauh lebih besar daripada luasan kaca jendela pada kulit bangunan.
\end{abstract}

Kata kunci : beban panas, dinding, hemat energi, kaca jendela, material

\section{PENDAHULUAN}

Nilai U-Value mempengaruhi besarnya aliran panas yang masuk ke dalam bangunan. Semakin tinggi nilai $U$-Value suatu material maka semakin besar panas yang masuk ke dalam bangunan. Kulit bangunan adalah elemen bangunan paling luar dalam suatu bangunan. Nilai $U$-value pada

PAWON: Jurnal Arsitektur, Nomor 02 Volume 3, Juli-Desember Tahun 2019, ISSN 2597-7636 
dinding, atap, pintu, dan kaca jendela dalam suatu bangunan memberikan pengaruh akan besarnya panas yang diterima bangunan. Dengan mengganti atap yang sebelumnya menggunakan atap rangka kayu dengan penutup atap genteng keramik menjadi atap dag beton tebal $15 \mathrm{~cm}$ yang dilapisi rock wool tebal $5 \mathrm{~cm}$ dan mengganti kaca single glass menjadi kaca double glass-low $E$ mampu menurunkan suhu sebesar $4,27^{\circ} \mathrm{C}$ pada sebuah rumah produksi batik di Cirebon (Nurwidyaningrum dkk, 2015:90).

Jenis material kulit bangunan mempengaruhi besarnya konsumsi energi. Penggantian material kaca jendela dari Single Glass menjadi Double Glass-Low E pada Gedung Campus Centre Barat ITB mampu menurunkan konsumsi energi dari $155 \mathrm{kWh} / \mathrm{m}^{2} /$ tahun menjadi $124 \mathrm{kWh} / \mathrm{m}^{2} /$ tahun (Vidiyanti, 2015:6). Hal itu disebabkan kaca Double Glass mempunyai rongga udara di antara kacanya sehingga menghambat aliran panas masuk ke dalam bangunan. Kaca Low-E mampu menangkal sinar matahari yang menimbulkan panas tetapi meneruskan cahaya yang dapat terlihat (visible light). Biaya pemakaian energi pada Gedung Campus Centre Barat ITB berkurang dari 32.877 dollar per tahun menjadi 26.244 dollar per tahun (Vidiyanti, 2015:6).

Kulit bangunan menerima panas matahari secara konduksi, konveksi, ventilasi, evaporasi, dan radiasi. Dengan perhitungan menggunakan software Ecotect, bangunan Gedung E., Fakultas IImu Administrasi, Universitas Brawijaya, Malang dihitung perpindahan panasnya yang terjadi pada kulit bangunan. Hasilnya adalah perpindahan panas secara radiasi yang melewati kaca jendela adalah yang paling besar, yaitu: sebesar $89 \%$ sedangkan perpindahan panas yang paling kecil adalah yang terjadi secara konduksi pada kaca jendela (3\%) (Limijana dkk, 2018:5).

Perumahan-perumahan sederhana dengan tipe kecil mempunyai perbedaan jenis material bangunan yang tergantung dengan harga jualnya. Semakin mahal harga suatu rumah maka semakin bagus material yang digunakan untuk kulit bangunannya. Material yang padat dan tebal mempunyai harga lebih mahal daripada material yang tipis dan berongga. Material yang padat dan tebal cenderung lebih bisa menghambat aliran panas masuk ke dalam bangunan daripada material yang tipis dan berongga. Semakin besar aliran panas yang masuk ke dalam bangunan menyebabkan bangunan menjadi lebih panas sehingga beban pendinginan menjadi lebih besar yang membuat semakin boros energi. Berdasarkan permasalahan tersebut maka penelitian ini bertujuan mengetahui material dinding dan kaca jendela rumah sederhana yang hemat energi berdasarkan perhitungan solar heat gain (Qs) dengan menggunakan simulasi Ecotect. 


\section{TINJAUAN PUSTAKA}

Suatu bangunan merupakan suatu sistem keseimbangan termal, dimana ada panas masuk dan panas keluar yang analog dengan keseimbangan termal pada tubuh manusia. Adapun persamaan keseimbangan termal pada bangunan adalah sebagai berikut (Szokolay, 2004:34):

$$
Q i+Q c+Q s+Q v+Q e=\Delta S
$$

$$
\text { Keterangan: } \begin{aligned}
Q \mathrm{i}=\text { internal heat gain } \\
Q c=\text { conduction heat gain or loss } \\
Q s=\text { solar heat gain } \\
Q v=\text { ventilation heat gain or loss } \\
Q e=\text { evaporative heat loss } \\
\Delta S=\text { a change in heat stored in the building }
\end{aligned}
$$

Berdasarkan persamaan di atas dapat diketahui bahwa sistem termal pada bangunan dipengaruhi oleh beban panas akibat aktivitas di dalam bangunan (Qi) dan beban panas yang terjadi secara konduksi (Qc), radiasi matahari (Qs), ventilasi $(\mathrm{Qv})$, serta evaporasi $(\mathrm{Qe})$. Jika keseimbangan termal terjadi pada bangunan maka nilai $\Delta S$ adalah 0 (Szokolay, 2004:34).

\section{METODE PENELITIAN}

Penelitian ini merupakan penelitian lanjutan dari penelitian yang berjudul "Pengaruh Jarak antar Bangunan dan Orientasi Bangunan terhadap Penghematan Energi pada Perumahan Sederhana". Hasil penelitian tersebut adalah perumahan yang berjarak 1 meter dengan orientasi ke arah selatan adalah perumahan yang paling hemat energi (Sabtalistia, 2018). Studi kasus yang digunakan sama dengan penelitian sebelumnya, yaitu rumah tipe 27/60 di Blok H11, No.2, Cluster the Village, Perumahan Forest Hill, Parung Panjang, Kabasiran, Bogor. Rumah tersebut mempunyai luas bangunan $27 \mathrm{~m}^{2}$ dan luas tanah $60 \mathrm{~m}^{2}$. Rumah yang dijadikan studi kasus adalah sebuah rumah yang menghadap barat daya (Gambar 1). Posisi rumah berada di hook karena berada di ujung jalan. Pengukuran menggunakan meteran laser digital dilakukan untuk membuat gambar denah, potongan, dan modelling 3d di Ecotect (Gambar 2). Rumah ini mempunyai 1 pintu depan, 2 jendela depan, 1 pintu belakang, dan 2 jendela belakang (Gambar 3). Samping kiri dan belakang rumah merupakan lahan hijau. Samping kanan rumah masih lahan kosong karena belum ada pembangunan rumah. Ruangan yang ada di dalamnya terdiri dari: 1 buah ruang tamu, 2 buah ruang tidur, dan 1 buah km/wc (Gambar 3). Atap rumah 
menggunakan 2 buah atap pelana yang mempunyai perbedaan ketinggian (Gambar 4).

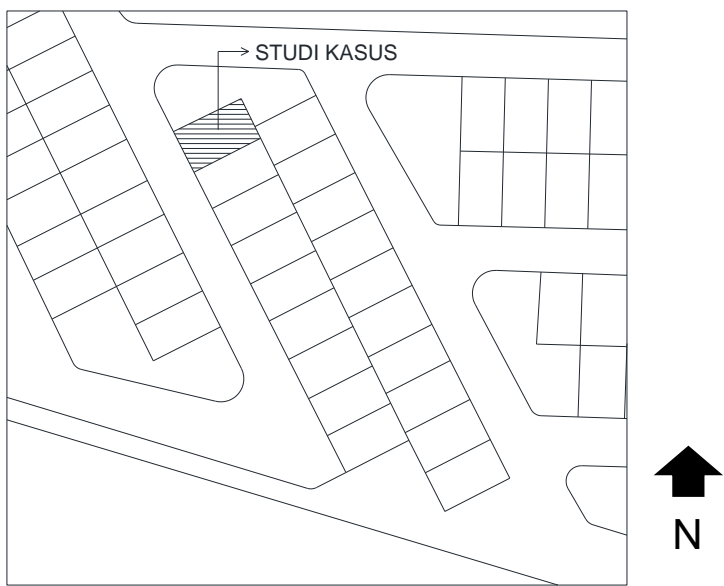

Gambar. 1 Posisi Studi Kasus (Blok H11, No.2) dalam Perumahan Forest Hill Sumber: Survei, Agustus 2018
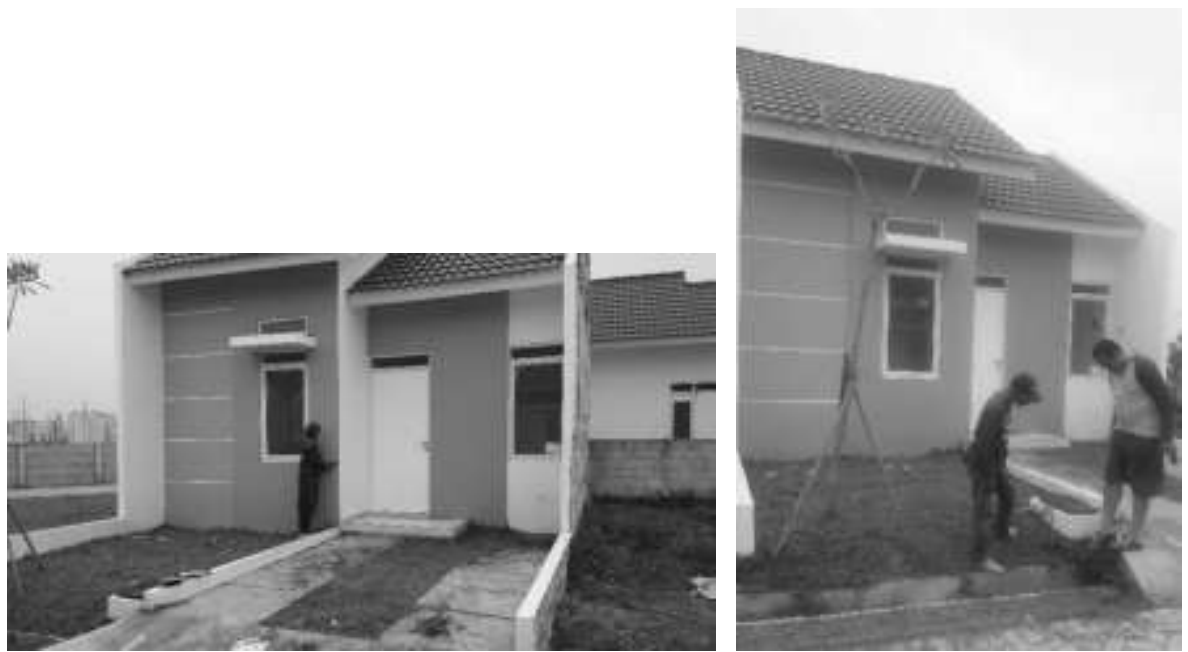

Gambar. 2 Pengukuran Studi Kasus dengan Meteran Laser Sumber: Survei, Agustus 2018

Material dinding dari batu bata batako (brick plaster) yang diplester dan dicat. Pintu depan dan pintu belakang menggunakan pintu double teakwood, kaca jendela menggunakan single glass tebal $6 \mathrm{~mm}$ dengan 
kusen aluminium, dan atap menggunakan rangka baja ringan dengan penutup atap genteng keramik (Gambar 2 dan 4).

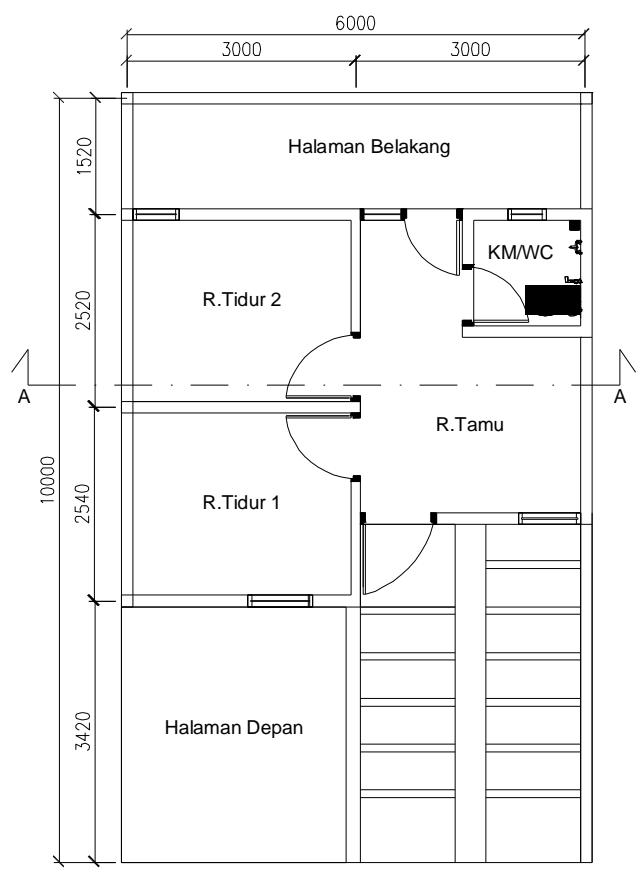

Gambar. 3 Denah Studi Kasus (Scale to Fit) Sumber: Survei, Agustus 2018

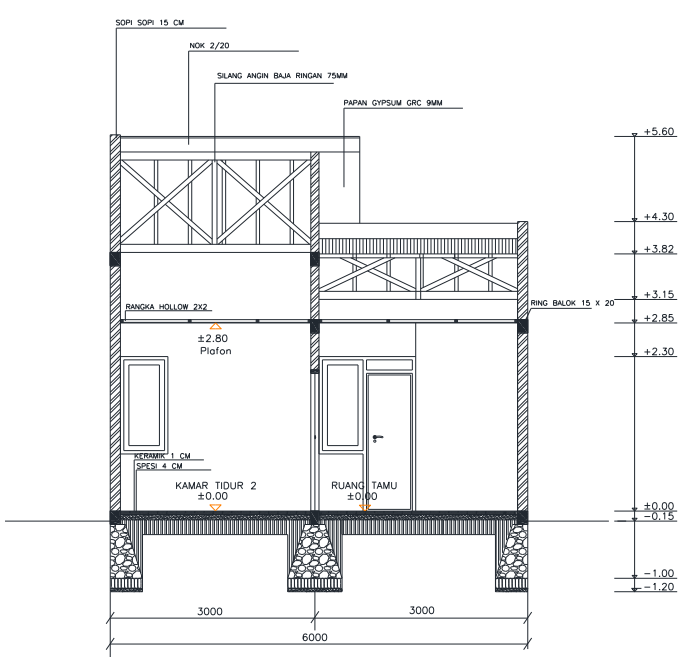

Gambar.4 Potongan A-A Studi Kasus (Scale to Fit) Sumber: Survei, Agustus 2018 
Penelitian ini menggunakan metode eksperimen dengan simulasi Ecotect Analysis 2011. Langkah pertama dalam perhitungan solar heat gain dengan Ecotect adalah membuat modelling 3 dimensi studi kasus sesuai dengan hasil pengukuran di lapangan (Gambar 5). Rumah disimulasikan berdiri sendiri (tidak berbatasan dengan bangunan lainnya) dan diarahkan ke barat daya sesuai dengan kondisi sebenarnya di lapangan (eksisting). Material dinding yang ada di lapangan (kondisi eksisting) menggunakan dinding batu bata batako (brick plaster) (Tabel 1). Kaca jendela kondisi eksisting menggunakan kaca jendela single glass tebal $6 \mathrm{~mm}$ dan kusen aluminium (single glazed aluminium frame). Untuk mengetahui pengaruh perubahan material dinding dan kaca jendela terhadap solar heat gain maka dilakukan eksperimen pengubahan material dinding menjadi double brick solid plaster dan double brick cavity plaster serta pengubahan material kaca jendela menjadi double glazed aluminium frame dan double glazed Low-E aluminium frame.

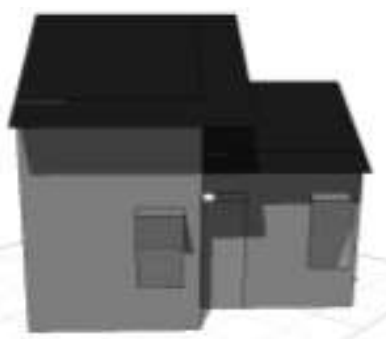

Gambar.5 Penggambaran Modelling Studi Kasus dengan Ecotect Sumber: Permodelan dengan Ecotect, September 2018

Tabel 1. Jenis Material dan Nilai $U$-Value pada Kondisi Eksisting dan Eksperimen

\begin{tabular}{|c|c|c|c|c|c|c|}
\hline No & Elemen & Eksisting & Eksperimen 1 & $\begin{array}{l}\text { Eksperrimen } \\
2\end{array}$ & Eksperimen 3 & $\begin{array}{c}\text { Eksperimen } \\
4\end{array}$ \\
\hline 1 & Lantai & $\begin{array}{l}\text { Concrete Slab } \\
\text { Tiles on Ground } \\
\left(0,88 \mathrm{~W} / \mathrm{m}^{2} \mathrm{~K}\right)\end{array}$ & $\begin{array}{l}\text { (Sama dengan } \\
\text { Eksisting) }\end{array}$ & $\begin{array}{c}\text { (Sama } \\
\text { dengan } \\
\text { Eksisting) }\end{array}$ & $\begin{array}{l}\text { (Sama dengan } \\
\text { Eksisting) }\end{array}$ & $\begin{array}{c}\text { (Sama } \\
\text { dengan } \\
\text { Eksisting) }\end{array}$ \\
\hline 2 & Dinding & $\begin{array}{l}\text { Brick Plaster } \\
\left(2,62 \mathrm{~W} / \mathrm{m}^{2} \mathrm{~K}\right)\end{array}$ & $\begin{array}{l}\text { Double Brick } \\
\text { Solid Plaster } \\
\left(1,95 \mathrm{~W} / \mathrm{m}^{2} \mathrm{~K}\right)\end{array}$ & $\begin{array}{c}\text { (Sama } \\
\text { dengan } \\
\text { Eksisting) }\end{array}$ & $\begin{array}{c}\text { Double Brick } \\
\text { Cavity Plaster } \\
\left(1,78 \mathrm{~W} / \mathrm{m}^{2} \mathrm{~K}\right)\end{array}$ & $\begin{array}{c}\text { (Sama } \\
\text { dengan } \\
\text { Eksisting) }\end{array}$ \\
\hline 3 & $\begin{array}{c}\text { Kaca } \\
\text { Jendela }\end{array}$ & $\begin{array}{l}\text { Single Glazed } \\
\text { Aluminium } \\
\text { Frame }(6 \\
\left.W / m^{2} K\right)\end{array}$ & $\begin{array}{l}\text { (Sama dengan } \\
\text { Eksisting) }\end{array}$ & $\begin{array}{c}\text { Double } \\
\text { Glazed } \\
\text { Aluminium } \\
\text { frame }(2,7 \\
\left.W / m^{2} K\right)\end{array}$ & $\begin{array}{l}\text { (Sama dengan } \\
\text { Eksisting) }\end{array}$ & $\begin{array}{c}\text { Double } \\
\text { Glazed Low- } \\
E \\
\text { Aluminium } \\
\text { Frame }(2,41 \\
\left.W / m^{2} K\right)\end{array}$ \\
\hline 4 & Pintu & $\begin{array}{c}\text { Hollow Core } \\
\text { Plywood }(2,98 \\
\left.W / m^{2} K\right)\end{array}$ & $\begin{array}{l}\text { (Sama dengan } \\
\text { Eksisting) }\end{array}$ & $\begin{array}{c}\text { (Sama } \\
\text { dengan } \\
\text { Eksisting) }\end{array}$ & $\begin{array}{l}\text { (Sama dengan } \\
\text { Eksisting) }\end{array}$ & $\begin{array}{c}\text { (Sama } \\
\text { dengan } \\
\text { Eksisting) } \\
\end{array}$ \\
\hline 5 & Atap & $\begin{array}{c}\text { Clay Tiled Roof } \\
\left(3,1 \mathrm{~W} / \mathrm{m}^{2} \mathrm{~K}\right)\end{array}$ & $\begin{array}{l}\text { (Sama dengan } \\
\text { Eksisting) }\end{array}$ & $\begin{array}{l}\text { (Sama } \\
\text { dengan } \\
\text { Eksisting) }\end{array}$ & $\begin{array}{l}\text { (Sama dengan } \\
\text { Eksisting) }\end{array}$ & $\begin{array}{l}\text { (Sama } \\
\text { dengan } \\
\text { Eksisting) }\end{array}$ \\
\hline
\end{tabular}

Sumber: Eksperimen dengan Ecotect, 2018 
Material lantai, pintu, dan atap tidak diubah (sama dengan kondisi eksisting) (Tabel 1). Nilai U-Value dinding yang terendah yang dieksperimen adalah dinding double brick cavity plaster $\left(1,78 \mathrm{~W} / \mathrm{m}^{2} \mathrm{~K}\right)$ (Tabel 1). Nilai $U$ Value kaca jendela terendah yang dieksperimen adalah kaca jendela double glazed Low-E aluminium frame $\left(2,41 \mathrm{~W} / \mathrm{m}^{2} \mathrm{~K}\right)$.

\section{HASIL DAN PEMBAHASAN}

Dengan mengganti material dinding menjadi double brick cavity plaster yang mempunyai nilai $U$-Value dinding cukup rendah maka bangunan menjadi lebih dingin karena panas matahari yang diterima bangunan menjadi lebih kecil. Solar heat gain yang diperoleh jika dinding bangunan menggunakan double brick cavity plaster adalah sebesar 279470 Wh. Penggantian material dinding brick plaster menjadi double brick cavity plaster mampu menghemat energi sebesar 43566 Wh per tahunnya. Dinding mempunyai luasan yang lebih besar daripada kaca jendela sehingga dengan mengganti material dinding dapat lebih efektif mengurangi perolehan solar heat gain daripada mengganti material kaca jendela (Gambar 6).

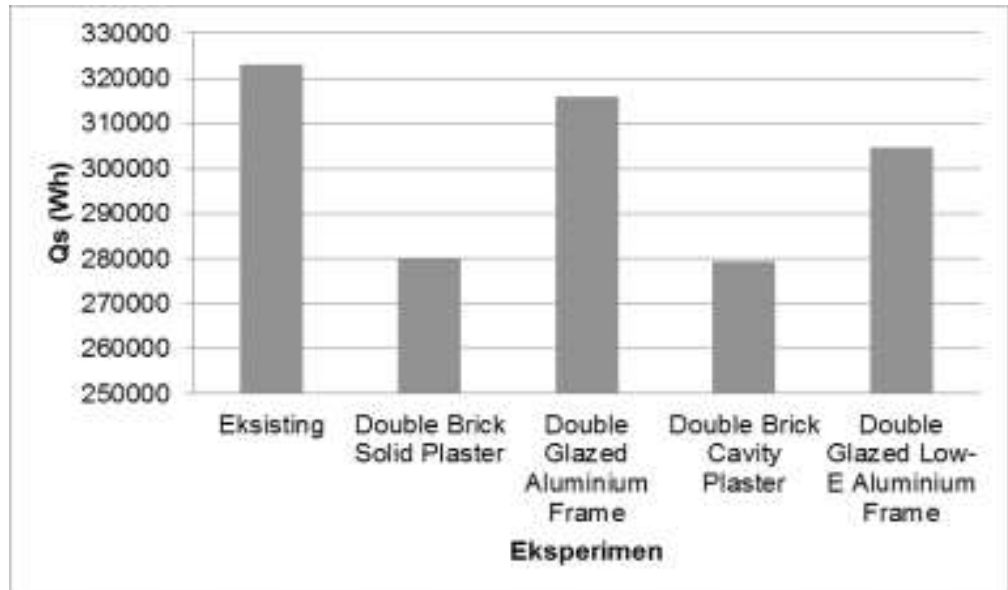

Gambar.6 Perolehan Solar Heat Gain (Qs) dalam 1 Tahun

Sumber: Perhitungan dengan Ecotect, September 2018

Tabel 2. Peringkat Solar Heat Gain (Qs) dalam 1 Tahun

\begin{tabular}{llc}
\hline & Qs $($ Wh $)$ & Peringkat \\
\hline Eksisting & 323036 & 5 \\
\hline Double Brick Solid Plaster & 280313 & 2 \\
\hline Double Glazed Aluminium Frame & 315838 & 4 \\
\hline Double Brick Cavity Plaster & 279470 & 1 \\
\hline Double Glazed Low-E Aluminium Frame & 304577 & 3 \\
\hline
\end{tabular}

Sumber: Perhitungan dengan Ecotect, September 2018

PAWON: Jurnal Arsitektur, Nomor 02 Volume 3, Juli-Desember Tahun 2019, ISSN 2597-7636 
Jika diurutkan berdasarkan perolehan solar heat gain, material yang paling mampu mengurangi nilai Qs (paling hemat energi) adalah double brick cavity plaster (peringkat 1 ) sedangkan material yang paling tidak mampu mengurangi nilai Qs (paling boros energi) adalah material eksisting dimana dindingnya menggunakan dinding bata (brick plaster) dan kaca jendelanya menggunakan single glazed aluminium frame (Peringkat 5) (Tabel 2).

Dinding double brick cavity plaster mempunyai rongga udara sebesar $5 \mathrm{~cm}$ (Gambar 7). Rongga udara tersebut efektif dalam mengurangi panas yang masuk ke dalam bangunan. Dinding double brick solid plaster mempunyai ketebalan hampir 2 kali lebih tebal daripada dinding brick plaster. Dinding brick plaster mempunyai ketebalan $13 \mathrm{~cm}$ sedangkan dinding double brick solid plaster mempunyai ketebalan $23 \mathrm{~cm}$ (Gambar 8). Oleh karena dinding double brick solid plaster lebih tebal daripada dinding brick plaster maka solar heat gain dinding double brick solid plaster lebih kecil daripada dinding brick plaster. Hal tersebut membuktikan bahwa semakin tebal suatu material maka semakin mampu material tersebut mendinginkan bangunan karena perolehan solar heat gain menjadi semakin kecil.

\begin{tabular}{|c|c|c|c|c|c|c|}
\hline \multicolumn{2}{|r|}{$\begin{array}{l}\text { Wood Virginia Pine (Across } \\
\text { Wood White Fir (A.cross Gre } \\
\text { Wood White Pine (Across E } \\
\text { Woodwool } \\
\text { Woodwool Board, Cement E } \\
\text { Woodwool Roofing Slabs } \\
\text { Woodwool, Xylolite Cement } \\
\text { Wool } \\
\text { Wool Felt Underlay } \\
\text { Wool, Fibrous } \\
\text { Wool, Resin Bonded }\end{array}$} & $\begin{array}{l}\text { 몋 } \\
5 \\
5\end{array}$ & & & & \\
\hline \multicolumn{7}{|c|}{ Calculate Thermal Properties } \\
\hline & Layer Name & Width & Density & Sp.Heat & Conduct. & Type \\
\hline 1. & Brick Masonry Medium & 110.0 & 2000.0 & 836.800 & 0.711 & 25 \\
\hline 2. & Air Gap & 50.0 & 1.3 & 1004.000 & 5.560 & 5 \\
\hline 3. & Brick Masonry Medium & 110.0 & 2000.0 & 836.800 & 0.711 & 25 \\
\hline 4. & Plaster Building (Molded Dry & 10.0 & 1250.0 & 1088.000 & 0.431 & 85 \\
\hline
\end{tabular}

Gambar.7 Potongan Dinding Double Brick Cavity Plaster Sumber: Ecotect Analysis 2011

Rongga udara sebesar $3 \mathrm{~cm}$ pada kaca double glazed mampu menghambat panas yang masuk ke dalam bangunan (Gambar 9). Lapisan Low- $E$ juga mampu menangkal panas matahari agar tidak masuk tetapi tetap mengijinkan cahaya matahari yang dibutuhkan untuk penerangan masuk ke dalam ruangan. Penggunaan kaca jendela double glazed Low- $E$ aluminium frame terbukti lebih efektif mengurangi panas yang diterima bangunan daripada kaca jendela double glazed aluminum frame (Gambar 6 dan tabel 2). 

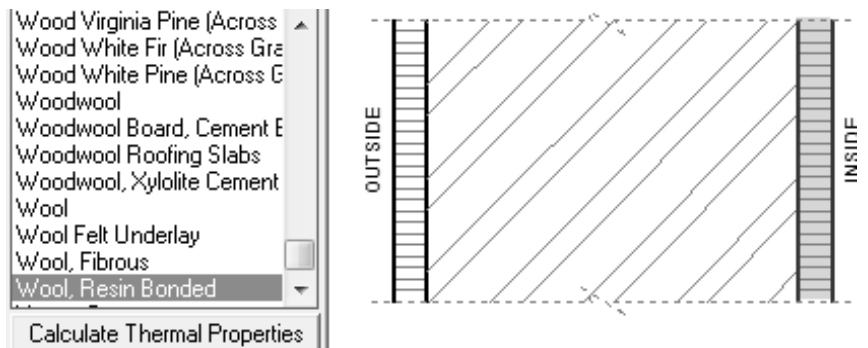

\begin{tabular}{|l|l|l|l|l|l|l|}
\hline & Layer Name & Width & Density & Sp. Heat & Conduct. & Type \\
\hline 1. & Plaster Building (Molded Dry 10.0 & 1250.0 & 1088.000 & 0.431 & 85 \\
\hline 2. & Brick Masonry Medium & 110.0 & 2000.0 & 836.800 & 0.711 & 25 \\
\hline 3. & Plaster Building (Molded Dry 10.0 & 1250.0 & 1088.000 & 0.431 & 85 \\
\hline
\end{tabular}

(a)

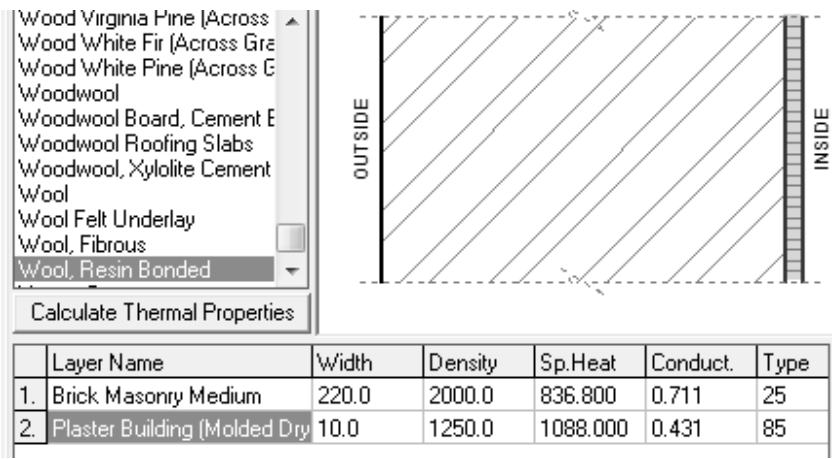

(b)

Gambar.8 Potongan Dinding: (a) Brick Plaster; (b) Double Brick Solid Plaster Sumber: Ecotect Analysis 2011

\begin{tabular}{l} 
Wood Virginia Pine (Across \\
Wood White Fir (Across Gre \\
Wood White Pine (Across E \\
Woodwool \\
Woodwool Board, Cement E \\
Woodwool Roofing Slabs \\
Woodwool, Xylolite Cement \\
Wool \\
Wool Felt Underlay \\
Wool, Fibrous \\
Wool, Resin Bonded \\
Calculate Thermal Properties \\
\hline
\end{tabular}

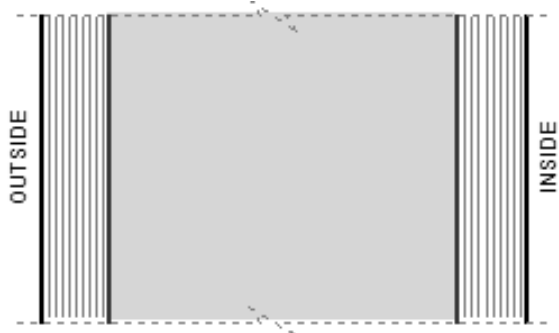

\begin{tabular}{|l|l|l|l|l|l|l|}
\hline & Layer Name & Width & Density & Sp. Heat & Conduct. & Type \\
\hline 1. & Glass Standard & 6.0 & 2300.0 & 836.800 & 1.046 & 75 \\
\hline 2. & Air Gap & 30.0 & 1.3 & 1004.000 & 5.560 & 5 \\
\hline 3. & Glass Standard & 6.0 & 2300.0 & 836.800 & 1.046 & 75 \\
\hline
\end{tabular}

Gambar.9 Potongan Kaca Jendela Double Glazed Low-E Aluminium Frame Sumber: Ecotect Analysis 2011

PAWON: Jurnal Arsitektur, Nomor 02 Volume 3, Juli-Desember Tahun 2019, ISSN 2597-7636 


\section{KESIMPULAN}

Salah satu cara untuk menghemat energi pendinginan adalah mengurangi beban panas akibat radiasi matahari pada kulit bangunan (Solar Heat Gain/Qs). Material yang mempunyai nilai $U$-Value lebih rendah mampu mengurangi panas yang masuk ke dalam bangunan. Penggantian material dinding brick plaster menjadi double brick cavity plaster mampu menghemat energi sebesar $43566 \mathrm{Wh}$ per tahunnya. Penggantian material kaca jendela single glazed aluminium frame menjadi kaca jendela double glazed Low-E aluminium frame juga mampu menghemat energi sebesar $18459 \mathrm{Wh}$ per tahunnya.

Hasil eksperimen membuktikan bahwa dinding double brick cavity plaster paling hemat energi karena paling mampu mengurangi perolehan solar heat gain. Penggantian material dinding lebih berpengaruh terhadap penurunan nilai solar heat gain karena luasan dinding jauh lebih besar daripada luasan kaca jendela. Kaca jendela double glazed Low-E aluminium frame juga lebih mampu mengurangi solar heat gain daripada kaca jendela double glazed aluminium frame. Lapisan Low-E pada kaca double glazed terbukti efektif mengurangi panas yang masuk ke dalam bangunan.

Sebagian besar rumah tinggal mempunyai carport yang menggunakan penutup kaca, asbes, seng, U-PVC, dsb. Perbedaan material penutup atap carport menyebabkan perbedaan penerimaan panas yang diterima. Rencana penelitian selanjutnya adalah menemukan material penutup atap carport yang paling bisa mengurangi panas.

\section{DAFTAR PUSTAKA}

Limijana Maharani dan Suryokusumo Beta. (2018), "Pengaruh Elemen Tembus Cahaya terhadap Nilai Perpindahan Termal pada Fasad Bangunan", Jurnal Mahasiswa Jurusan Arsitektur Universitas Brawijaya, Vol.6, No.3, Hal.1-10.

Nurwidyaningrum Dyah, A.G, Hidjan, Farida, R. (2015), Pengaruh Material Ruang pada Kenyamanan Termal Ruang Membatik yang Menggunakan Skylight Studi Kasus: Rumah Batik Katura, Plered, Cirebon", Jurnal Tesa Arsitektur, Vol.13, No.2, Hal.81-92.

Sabtalistia, Y.A. (2019), "Pengaruh Jarak antar Bangunan dan Orientasi Bangunan terhadap Penghematan Energi pada Perumahan Sederhana", Jurnal IImiah ARJOUNA, Vol.03, No.02, Hal.47-53.

Szokolay, S.V. (2004), Introduction to Architectural Science, The Basis of Sustainable Design, Oxford, Burlington, Britain.

Vidiyanti, C. (2015), "Kajian Retrofit Bangunan sebagai Upaya Mereduksi Konsumsi Energi Operasional" , Jurnal Arsitektur, Bangunan, \& Lingkungan, Vol.5, No.1, Hal.1-9. 